\title{
Diversidade de aves em parques eólicos na APA Delta do Parnaíba, Nordeste, Brasil
}

\section{Ocivana Araujo Pereira $^{1 *}$, Arthur Serejo Neves Ribeiro², Suely Silva Santos ${ }^{3}$, Airton Janes da Silva Siqueira 4 , Muryllo dos Santos Nascimento ${ }^{5}$, Francisco das Chagas Vieira Santos ${ }^{6}$, Anderson Guzzi ${ }^{7}$}

\author{
1 Mestrando do Programa de Mestrado em Desenvolvimento e Meio Ambiente (PRODEMA), Universidade Federal do Piauí, Avenida Universitária, \\ $n^{\circ} 1310$, Teresina, PI, Brasil. \\ 2 Mestre. Universidade Federal do Maranhão, Campus de São Bernardo. Rua Projetada, Centro, CEP 65550-000, São Bernardo, Maranbão, Brasil \\ 3 Doutoranda. Programa de Doutorado em Desenvolvimento e Meio Ambiente (PRODEMA)- Em Rede. Universidade Federal do Piauí, Teresina, PI, Brasil. \\ Piaui, Brasil. \\ 4 Mestrando. Programa de Mestrado em Desenvolvimento e Meio Ambiente (PRODEMA), Universidade Federal do Piauí, Avenida Universitária, $n^{\circ} 1310$, \\ Teresina, PI, Brasil. \\ 5 Doutorando. Programa de Doutorado em Desenvolvimento e Meio Ambiente (PRODEMA) - Em Rede. Universidade Federal do Piani, Teresina, PI, \\ Brasil. Piaui, Brasil. \\ 6 Doutorando. Programa de Doutorado em Desenvolvimento e Meio Ambiente (PRODEMA) - Em Rede. Universidade Federal do Piauí, Teresina, PI, \\ Brasil. Piaui, Brasil. \\ 7 Doutor. Professor. Centro de Ciências do Mar, Universidade Federal do Piani Av. São Sebastião, 2819, Planalto Horizonte, 64202-020, Parnaíba, Piauí, \\ Brasil. \\ * Autor para correspondência: ocivanaaraujo@gmail.com
}

Recebido em 27 de fevereiro de 2019. Aceito em 23 de dezembro de 2019. Publicado em 30 de dezembro de 2019.

Resumo - Parques eólicos são produtores de energia limpa por apresentarem baixo impacto ambiental, além de possibilitar a renovação dos recursos naturais. No entanto, alguns grupos de fauna são mais afetados, como é o caso das aves. Outro fato importante são os impactos oriundos da perda de habitat natural decorrente da implantação das estradas de acesso e linhas de transmissão. Com isso o presente trabalho tem como objetivo relacionar a composição e dinâmica das espécies de aves presentes com os possíveis impactos causados pelos Parques Eólicos Testa Branca I e III. O trabalho foi realizado nos Parques Eólicos Testa Branca I e III localizados no município de Ilha Grande, Piauí. Foram realizadas quatro campanhas, nos meses de fevereiro e julho, dos anos de 2017 e 2018. Os métodos utilizados foram o ponto de escuta e captura por rede de neblina (mist nets). A amostragem resultou no registro de 9.136 contatos e 74 capturas, com indivíduos pertencentes a 102 espécies, distribuídas em 20 ordens e 41 famílias. Além dos registros obtidos, quatro indivíduos mortos devido a colisões com aerogeradores foram registrados. Das espécies registradas duas espécies apresentam algum grau de ameaça, tanto na lista da IUCN quanto na lista nacional de animais ameaçados de extinção.

Palavras-chave: Biodiversidade; Aves; Energia eólica; Monitoramento.

\section{Bird Diversity in wind farms at APA Delta Parnaíba, Northeast, Brazil}

Aвstract - Wind farms are producers of clean energy because they have a low environmental impact, as well as enabling the renewal of natural resources. However, some groups of fauna are more affected, as is the case of birds. Another important fact is the impacts arising from the loss of natural habitat resulting from the implementation of access roads and transmission lines. This work aims to relate the composition and dynamics of the bird species with the possible impacts caused by Testa Branca I and III Wind Farms. The work was carried out at the Testa Branca I and III Wind Farms located in the municipality of Ilha Grande, Piauí. Four campaigns were carried out in the months of February and July of the years 2017 and 2018. The methods used were the listening point and mist nets. The sampling resulted in the registration of 9,136 
contacts and 74 captures, with individuals belonging to 102 species, distributed in 20 orders and 41 families. In addition to the records obtained, four individuals killed due to collisions with wind turbines were registered. Of the species registered, two species present some degree of threat, both in the IUCN list and on the national list of animals threatened with extinction.

KEY wORDs: Biodiversity; Birds; Wind energy; Monitoring.

\section{Diversidad de aves en parques eólicos en APA Delta Parnaíba, Nordeste, Brasil}

Resumen - Los parques eólicos son productores de energía limpia por presentar un bajo impacto ambiental, además de permitir la renovación de los recursos naturales. Sin embargo, algunos grupos de fauna son más afectados, como es el caso de las aves. Otro hecho importante son los impactos provenientes de la pérdida de hábitat natural resultante de la implantación de las carreteras de acceso y líneas de transmisión. Por ello, este trabajo tiene como objetivo relacionar la composición y dinámica de las especies de aves presentes con los posibles impactos causados por los Parques Eólicos Testa Branca I y III. El trabajo fue realizado en los Parques Eólicos Testa Branca I y III ubicados en el municipio de Ilha Grande, Piauí. Se han llevado a cabo cuatro campañas, en los meses de febrero y julio, de los años 2017 y 2018. Los métodos utilizados fueron el sitio de escucha y captura por red de neblina (mist nets). El muestreo resultó en el registro de 9.136 contactos y 74 capturas, con individuos pertenecientes a 102 especies, distribuidas en 20 órdenes y 41 familias. Además de los registros obtenidos, se han registrado también las muertes de cuatro individuos debido a colisiones con aerogeneradores. De los registros se encontraron dos especies presentan algún grado de amenaza, tanto en la lista de la IUCN cuanto en la lista nacional de animales amenazados de extinción.

Palabras clave: Biodiversidad; Aves; Energía eólica; Monitoreo.

\section{INTRODUÇÃO}

Parques eólicos são empreendimentos caracterizados como produtores de energia limpa por apresentar baixo impacto ambiental, além de possibilitar a renovação dos recursos naturais, não poluentes e não necessitam de combustíveis fósseis, não apresentando graves consequências ao ambiente (Macías et al. 2003; Saidur et al. 2011).

No entanto, alguns grupos de fauna são mais afetados, como as aves. Características desse tipo de empreendimento como tamanho, posição das turbinas e a velocidade de rotação dos aerogeradores são fatores que podem aumentar o impacto dos parques eólicos sobre a avifauna (Thelander et al. 2003). Animais de grande porte, espécies de hábitos noturnos ou que voam nas primeiras e últimas horas do dia possuem maior risco de colisão contra os aerogeradores (Larsen e Clausen 2002; Barrios e Rodriguez 2004). Aliado a isso, é importante considerar os impactos oriundos da perda de habitat natural decorrente da implantação das estradas de acesso e linhas de transmissão (Saidur et al. 2011).

A área de estudo está localizada em região litorânea, o que favorece a migração de diversas espécies de aves (Sick 1983), que saem do hemisfério norte no período próximo ao inverno boreal (Larrazábal et al. 2002). Estas aves vêm em busca de locais para invernada com oferta de alimento para completarem seu ciclo biológico (TelinoJunior et al. 2003).

Para a região norte do Piauí 224 espécies foram amostradas pertencendo a 23 famílias (Santos 2017; Santos 2018; Nascimento 2018) e na região do Delta do Parnaíba 139 espécies diferentes de aves, das quais 113 foram consideradas residentes, 8 endêmicas do Brasil e 17 visitantes do Hemisfério Norte (Guzzi et al. 2012).

O CEMAVE (Centro Nacional de Pesquisa para Conservação das Aves Silvestres) publica regularmente o Relatório Anual de Rotas e Áreas de Concentração de Aves Migratórias no Brasil, e nesse relatório, o Delta do Parnaíba é apontado como uma área de concentração de aves migratórias no Brasil, e destacado como área importante para sua conservação (Oliveira et al. 2016). Aliado a isso, todos os anos milhares de aves provenientes 
do Ártico migram para a América do Sul, devido à proximidade do outono boreal. Movimentam-se no sentido sul, onde várias espécies invernam, principalmente nas costas marítimas do continente, no período de setembro a abril (Cabral et al. 2006).

Dentro desse quadro é importante concentrar as pesquisas científicas nas espécies mais sensíveis, buscando identificar as aves que tem maior risco de serem afetadas pelas turbinas dos aerogeradores (Desholm 2009). Nesse sentido, o objetivo deste estudo foi relacionar a composição e dinâmica das espécies de aves presentes com os possíveis impactos causados pelos Parques Eólicos Testa Branca I e III, no município de Ilha Grande, Piauí.

\title{
Materiais e MÉtodos
}

\author{
Área Amostral
}

O trabalho foi realizado nos Parques Eólicos Testa Branca I e III ( $2^{\circ} 47 ’ 59.55^{\prime \prime}$ S/ 4147’32.07” O), que estão localizados no município de Ilha Grande, extremo norte do estado do Piauí. O empreendimento conta com 20 aerogeradores em uma linha reta, sendo dez aerogeradores pertencentes ao Parque Testa Branca I e dez ao Parque Testa Branca III. Os parques são contíguos, e se encontram inseridos na Área de Proteção Ambiental Delta do Parnaíba, criada a partir do Decreto Federal de 28 de agosto de 1996 (Brasil 1996).

Compreende uma área caracterizada por apresentar extensas planícies flúvios-marinhas cortadas por uma rede de canais, os quais formam as ilhas do Delta do Parnaíba. É notável a presença de extensas áreas de mangue, dunas móveis e áreas de tensão ecológica formadas por caatinga, cerrado e sistemas marinhos (Castro 2007; Andrade et al. 2012). Segundo a classificação de Köppen (1948), o clima da região é considerando quente e úmido (Aw) e, devido a influência da massa Equatorial Atlântica, os meses de janeiro a junho possuem alto índice de pluviosidade.

De acordo com a classificação proposta por Santos-Filho (2010), a região, uma área de restinga, possui três fisionomias vegetais básicas: formação campestre, arbustiva e arbórea. Seguindo a caracterização vegetacional dada pelo autor, os pontos amostrais, dispostos nos parques eólicos Testa Branca I e III, estão localizados em uma área com características semelhantes a uma Formação Arbustiva do tipo Fruticeto Aberto Inundável.

Um dos pontos encontram-se mais próximo a uma área de manguezal, um ecossitema característico de regiões tropicais e subtropicais que faz transição entre o ambiente terrestre como também o marinho. Possuem uma vegetação que se adequa às características do ambiente como a salinidade. Três gêneros vegetais constituem os manguezais brasileiros: Avicennia, Rhizophora e Laguncularia (Schaeffer-Novelli, 1986,1995).

\section{Monitoramento da Avifauna}

Foram realizadas quatro campanhas amostrais nos meses de fevereiro (período úmido) e julho (período seco), dos anos de 2017 e 2018, englobando dois ciclos sazonais completos. O período úmido é caracterizado pelo aumento da precipitação pluviométrica, promovendo o aumento dos corpos d'água permanentes e o surgimento de corpos d'água temporários. O período seco é caracterizado pela estiagem, que acarreta a redução do volume dos corpos d'água permanentes e a seca dos corpos d'água temporários. Cada campanha amostral teve duração de cinco dias, e o levantamento de dados ocorreu durante as duas primeiras e as duas últimas horas do dia, em um total de 40 horas amostrais.

Os métodos utilizados no monitoramento foram o ponto de escuta, de acordo com Bibby et al. (1992) e captura por rede de neblina (mist nets), como método complementar. A coleta de dados foi qualitativa (guildas tróficas, sensibilidade e habitat preferencial) e quantitativa (frequência de ocorrência, distribuição sazonal, índice de 
diversidade e equabilidade) e a área de estudo teve sua extensão coberta por cinco pontos amostrais equidistantes, de forma que os dois parques foram igualmente amostrados.

No Ponto de escuta as aves vistas e/ou ouvidas foram registradas com o auxílio de binóculos e câmera fotográfica com teleobjetiva. Foram utilizados binóculos $(10 \mathrm{X} 50 ; 10 \mathrm{X} 70)$ para o registro dos contatos visuais. Foram utilizados os manuais de campo de Dunning (1982), Ridgely e Tudor (1994) e Sigrist (2009) para auxiliar na identificação das espécies.

Foram armadas 20 redes de neblina (mist nets) de 2,5m X 3mm X 12m divididas em duas linhas de 10 redes em cada parque para a captura de aves permanecendo abertas das 4:00h as 8:00h pela manhã e das 16:00h as 20:00h, sendo vistoriadas a cada 20 minutos, em um total de $3.200 \mathrm{~h} /$ rede. As redes de neblina foram armadas preferencialmente nas áreas próximas a pequenos fragmentos residuais de vegetação nativa (mangue) e próxima a lagoas temporárias que pudessem abrigar aves migratórias.

Os pontos amostrais variaram em sua fisionomia, nos quais foi possível perceber a existência de uma diminuição de vegetação ao percorrer do primeiro (P1) ao quinto (P5) ponto. O ponto P1 possui uma faixa de vegetação mais densa e se localiza em área de mangue, ao passo que o ponto P5 se encontra em uma área de vegetação rasteira, com poucos arbustos e presença de dunas móveis. Os pontos de rede de neblina foram próximos ao ponto P1, de modo que fosse possível registrar as aves de difícil registro por meio de observação.

Durante o período amostral foi realizado o anilhamento da avifauna, com anilhas do tipo CEMAVE /ICMBio (Instituto Chico Mendes de Conservação da Biodiversidade), numeradas individualmente. Todas as aves capturadas foram medidas, pesadas, anilhadas, fotografadas, e depois libertadas no mesmo local, evitando contato duradouro com as mesmas. Nenhum espécime foi coletado. As principais medidas biométricas foram: comprimento da asa; comprimento e espessura do metatarso; comprimento do bico e comprimento da cauda. Além dessas medidas, também foi verificado se as aves capturadas apresentam placa de incubação, o que indica o período reprodutivo ou muda (presença de canhão do cálamo).

\section{Análise dos Dados}

Foram registrados os dados de Status de migração das espécies, seguindo Stotz (1996), Sensibilidade a atividades antrópicas, Uso do Habitat, Guildas Tróficas (Dieta), seguindo Motta Júnior (1990). Dados como Frequência de Ocorrência, Distribuição Sazonal das Espécies, Índice de Similaridade de Jaccard e o índice de diversidade de Shannon-Wiener e Equabilidade de Pielou também foram analisados.

A nomenclatura das espécies seguiu Piacentini et al. (2015), assim como os seus nomes populares e distribuição geográfica. As dietas foram determinadas através de registros de campo e bibliografia pertinente: Willis (1979) e Sick (1997).

Foi utilizada a classificação modificada de Naka et al. (2002) para Frequência de Ocorrência, na qual: espécies que apresentavam frequência $\geq 75 \%$ nas amostras foram consideradas Abundantes; quando $\geq 50 \% \mathrm{a}<75 \%$ foram consideradas Comuns; quando $\geq 25 \%$ a $<50 \%$ foram consideradas Escassas; quando em $<25 \%$, ocorrendo mais de uma vez, foram consideradas Raras e as que foram registrada apenas uma ocorrência foi classificada como ocasional.

Foi calculado o índice de Shannon $\left(\mathrm{H}^{\prime}\right)$ e Equabilidade de Pielou $(\mathrm{J})$ para avaliar a diversidade. O Índice de Shannon-Wiener varia de 1,5 a 3,5, podendo raramente ultrapassar o valor de 4,5, e a equabilidade varia entre 0 e 100\%, em que 100\% indica espécies igualmente abundantes no ambiente. Os valores revelam uma diversidade alta de espécies, as quais apresentam distribuição relativamente equilibrada (Cabral et al. 2006). Segundo Martins e Santos (1999), um baixo valor de equabilidade significa que existe a dominância de uma ou mais espécies na comunidade estudada, enquanto equabilidade alta significa distribuição uniforme entre as espécies na amostra. 


\section{Resultados e Discussão}

Foram registrados 9.136 contatos e foram capturados 74 indivíduos pertencentes a 102 espécies, distribuídas em 20 ordens e 40 famílias. O período úmido apresentou um maior número de espécies (74 no primeiro ano amostral e 60 no segundo), quando comparado ao período seco (57 e 55, respectivamente). O maior número de espécies foi registrado em P1 ( $\mathrm{n}=81)$, seguido de P3, P4 $(\mathrm{n}=40)$ e P2 $(\mathrm{n}=35)$ e com menor diversidade P5 (34 espécies). A amostragem por rede de neblina resultou na captura de 27 espécies, destas, seis foram registradas exclusivamente por este método, sendo elas: Calidris pusilla; Amazilia versicolor; Chloroceryle americana; Certhiaxis cinnamomeus; Myiozetetes cayanensis; Conirostrum b. bicolor; Conirostrum b. minus. Além dos registros obtidos, quatro indivíduos mortos devido a colisões com aerogeradores foram registrados. Na primeira amostragem foi registrado um urubu-de-cabeça-amarela (Cathartes burrovianus) e durante a quarta amostragem três urubus-de-cabeça-preta, Coragyps atratus.

De modo geral, P1 apresentou maior diversidade (riqueza e abundância), nas quatro amostras e P2 foi o que apresentou a menor em três das quatro amostras, ocorrendo uma diferença na riqueza registrada nos diferentes pontos amostrais. Quanto a abundância, uma única espécie, Thectocercus acuticaudatus, foi responsável por 40\% $(\mathrm{n}=3682)$ dos contatos de toda a amostra, contudo, mesmo com a exclusão desta espécie em P1, onde a espécie teve maior representatividade, continua como ponto mais abundante.

A variação na riqueza e composição de aves entre os pontos pode estar relacionada a variação do ambiente e a presença de água. Isto se deve provavelmente à fitofisionômia ou o habitat, pois a vegetação presente neste local apresenta maior quantidade de elementos e espécies vegetais, além da maior heterogeneidade de ambientes, pois a diversidade de aves que compõem a avifauna está relacionada ao grau de heterogeneidade do ambiente (Magurran 1988). O ponto P1 apresentava vegetação mais densa com presença de mangue e lagoas temporárias e permanentes, ocorrendo uma diminuição da vegetação à medida que se aproximava do ponto P5, que apresentou vegetação rasteira com poucos arbustos, presença de lagoas temporárias e dunas móveis. Entretanto, a resposta da diversidade de espécies a esta heterogeneidade possivelmente varia dependendo do grupo de espécies estudado e das variáveis selecionadas (Atauri e Lucio 2001).

Assim, alguns fatores como presença ou ausência de chuva, maior disponibilidade de recursos e a presença de lagoas permanentes, funcionam como ponte de conexão entre espécies, possibilitando uma série de serviços ecológicos como migração, alimentação e reprodução (Soares 2010). As flutuações de riqueza e composição entre pontos e amostragens envolve uma miríade de fatores bióticos e abióticos, mas pode estar associada à oferta e distribuição de alimento, o que pode ser confirmado por Walker (2006), que diz que as comunidades de aves sofrem flutuações naturalmente em função da oferta de alimentos.

A presença de pequenas lagoas, brejos e uma vegetação entremeada por campos inundáveis, incluindo manguezais também são fatores que podem ter contribuído para uma diversidade maior de espécies em P1. Nesta área também foi verificado uma ocorrência maior de aves limícolas, assim como outras espécies de aves que estão quase sempre associados a habitats aquáticos, como por exemplo: Fluvicola nengeta, Tachycineta albiventer, Megaceryle torquata, Gallinula galeata, Jacana jacana, e a grande maioria das espécies pertencentes à família Ardeidae, compostas por garças e socós (Sick 1997), a mais abundante neste estudo.

Cardoso et al. (2013), observaram que os locais que represavam água no Aeroporto Internacional de Parnaíba, atraem um grande número de espécies para este tipo de hábitat. Segundo Luigi et al. (2010) áreas como mangues, brejos, rios, lagoas, pântanos, deltas e florestas, entre outras áreas de retenção de água, são potenciais atrativos da avifauna. Olmos et al. (2005) também relatam que a disponibilidade de lagoas durante a estação chuvosa atrai um grande número de aves aquáticas para a região, se concentrando em algumas áreas.

Foi criada uma curva de acumulação de riqueza das espécies para a área utilizando o estimador Jackknife de Segunda Ordem (Jack 2) (Figura 1). Foi estimado uma riqueza esperada de aproximadamente 136 espécies, 
demonstrando que cerca de $75 \%$ das espécies presentes na área foram registradas através das técnicas de amostragem empregada. É possível observar que a curva de acumulação está próxima de alcançar a estabilidade.

Figura 1. Curva de acumulação de espécies observadas (Sobs) e estimadas, segundo Jackknife de segunda ordem (Jack2), durante o esforço amostral.

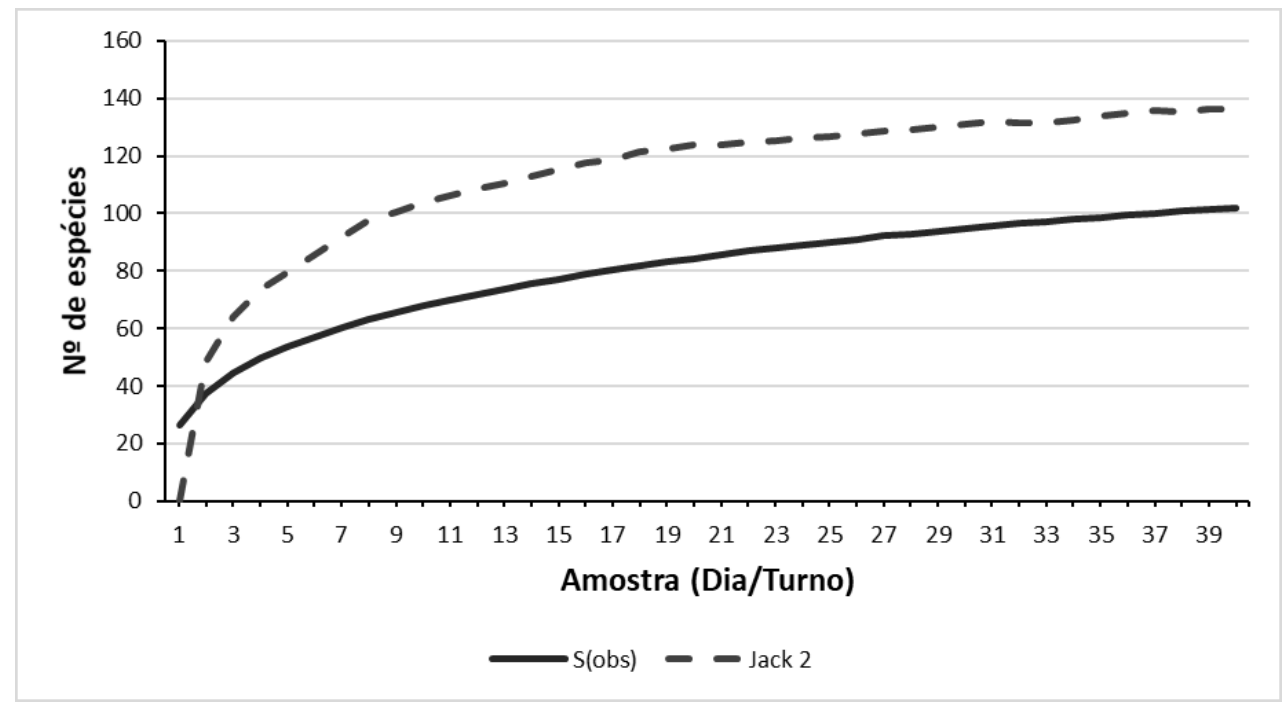

Fonte: Pesquisadora

A diversidade de Shannon mostrou uma variação durante a primeira amostragem de 2,05 a 2,59 entre os pontos amostrais. A segunda variou entre 1,72 e 2,61, enquanto a terceira variou de 1,02 a 2,69 e na quarta ocorreu uma variação de 1,84 a 2,76. Quanto a equabilidade de Pielou (J'), na primeira, segunda e quarta amostragens houve uma alta variação entre os diferentes pontos amostrais, indicando que há baixa dominância de espécies de aves, com resultados variando de 0,52 a 0,82 (primeira amostra), 0,65 a 0,84 (segunda amostra) e de 0,68 a. 0,87 (quarta amostra). Em relação à terceira campanha, três pontos amostrais apresentaram baixa equabilidade $(\mathrm{P} 1=0,43 \mathrm{P} 3=0,41$ e $\mathrm{P} 4=0,43)$ visto que a equabilidade é considerada alta quando maior que 0,50. Os menores valores quanto a equabilidade foram registrados em P1, e isso pode ser explicado pelo alto número de contatos da espécie T. acuticaudatus o que demostra dominância da espécie em relação as demais.

As espécies registradas estão distribuídas em 40 famílias, sendo possível observar a predominância de três: Ardeidae $(n=9)$, Icteridae $(n=8)$ e Tyrannidae $(n=8)$. Nos períodos úmidos ocorreram um maior número de famílias $(n=35$ e 30) em relação aos períodos secos ( $n=26$ e 27). Oito famílias ocorreram somente nos períodos úmidos, sendo elas: Bucconidae; Fregatidae; Furnariidae; Pandionidae; Passeridae; Polioptilidae; Rallidae; Thamnophilidae e Trochilidae. A família Podicipedidae ocorreu somente no segundo período seco, representada pela espécie Tachybaptus dominicus.

A família Ardeidae apresentou maior número de espécies na segunda e quarta amostragens, principalmente em P1. Isso pode estar relacionado a diminuição do volume das lagoas temporárias o que aumenta a concentração dos indivíduos em busca de água e alimento (peixes, insetos aquáticos, caranguejos, moluscos e alguns vertebrados). A família é representada pelas garças e socós e apresentam vasta distribuição (Sick 2001).

A família Tyrannidae, é considerada a família mais diversa nas savanas tropicais do mundo e representam a maior abundância de espécies do continente ocidental, ocorrendo principalmente nas Américas (Sick 2001). São essencialmente arborícolas, podendo ocorrer em todos os estratos da vegetação, sendo destaque em trabalhos como o de Marçal-Júnior et al. (2009), que em seu trabalho registrou 39 espécies (16,88\%) pertencentes a esta família. A predominância da família Tyrannidae também está presente em vários trabalhos em áreas de restinga e/ ou com predominância de vegetação de Caatinga, também é a família com maior riqueza de espécie em vegetação de Caatinga no estado do Piauí, mostrando assim a ampla distribuição desta família dentro do território piauiense (Santos 2004; Silveira e Machado 2012; Guzzi et al. 2012; Santos et al. 2012, Nunes e Machado 2012). 
As aves da família Icteridae encontram-se em todos os biomas do país, alimentam-se de insetos, artrópodes, pequenos vertebrados, sementes, frutos e em alguns casos néctar de flores. Inclui espécies de hábito arborícola, terrestre, florestais, facilmente encontradas em áreas de Floresta mista, matagal, áreas agrícolas, pântanos, penhascos rochosos e ambientes suburbanos, o que justifica a abundância da família nesta pesquisa (Sick 1997; Del Hoyo et al. 2011). Algumas aves desta família exibem um colorido exuberante, além de uma das vocalizações melodiosas, tal como Icterus jamacaii, e por isso, essa espécie é alvo d e comércio ilegal da fauna silvestre brasileira (Gama e Sassi 2008; Nobrega et al. 2012; Licariao et al. 2013; Silva et al., 2015).

Quanto ao status de migração das espécies, foi possível observar a dominância das espécies Residentes (R), n= 93, das quais 80 são espécies registradas como residentes, 11 são Residentes Parcialmente Migratórias (MPR) e duas espécies Residentes Endêmicas (R,E). Foram registradas ainda nove espécies migratórias, sendo seis Vagantes do Norte (VN, Pandion haliaetus; Charadrius semipalmatus; Actitis macularius; Tringa melanoleuca; Tringa flavipes e Calidris pusilla - e três Migrantes Austrais (A, Theristicus caudatus, Sternula superciliaris e Columbina picui- (Figura 2; Tabela 1).

A presença de uma menor quantidade de aves migratórias na segunda e quarta campanha quando comparada à primeira e à terceira campanha se deve ao período de realização das amostragens. Geralmente as aves migratórias chegam aos locais de invernada no período de agosto a setembro, permanecendo até abril, período de retorno para a área de reprodução (Larrazábal et al. 2002). A presença de espécies migratórias encontradas fora do período de migração pode ser explicada pelo fato destes indivíduos não conseguirem retornar ao seu ambiente de reprodução (Cabral et al. 2006).

As espécies migratórias $(\mathrm{VN})$ foram pouco representadas na área de estudo $(\mathrm{n}=6)$, tendo correspondido a apenas $6,5 \%$ do total de aves do hemisfério norte que visitam o território brasileiro. Este é um fato que pode estar relacionado à baixa disponibilidade de alimento para estas espécies na área de estudo, já que, em suas rotas de migração, vários habitats são selecionados, os quais estão relacionados aos hábitos alimentares, e devido à distribuição descontínua desses recursos as espécies geralmente se concentram em áreas específicas (CEMAVE 2016).

Áreas da América do Sul estão entre os locais utilizados como áreas de invernada por muitos Charadriiformes (Lunardi 2010). Bildstein et al. (1991) afirmam que essas áreas vêm sendo afetadas por atividades humanas, comprometendo, potencialmente, a sobrevivência de muitas populações de aves costeiras. A conservação de aves migratórias está diretamente relacionada com a identificação de sítios de alimentação, repouso e reprodução. Portanto, a perda de um sítio pode acarretar a diminuição e até mesmo a extinção local de alguma espécie. Por isso, trabalhos de monitoramento de populações migratórias são fundamentais para planejar ações de conservação das mesmas (Telino-Junior et al. 2003).

Onze guildas tróficas foram registradas, sendo a mais representativa a guilda onívora (ONI), variando entre 16 e 23 espécies ao longo das amostras e totalizando 29 espécies. A segunda mais representativa foi a insetívora (INS), variando de 12 a 21 espécies e totalizando 28. Para as guildas carnívora (CAR) e piscívora (PIS), foram registradas 12 espécies cada, ocorrendo uma variação de cinco a nove espécies por amostragem. As demais guildas apresentaram menos de seis espécies cada (Figura 2).

Quanto a abundância registrada para cada guilda, a guilda Frutívora/Granívora (FRU/GRA), mesmo sendo representada por uma única espécie (Thectocercus acuticaudatus) foi a mais abundante nos dois períodos úmidos com 3682 contatos. A segunda foi a guilda onívora $(\mathrm{n}=2761)$ sendo a mais abundante nos períodos secos (Figura 2). Diante da análise geral, se observa a predominância tanto em número de espécies quanto em contatos das aves onívoras, aquelas que apresentam uma alimentação baseada em fontes animais e vegetais, seguida das insetívoras, aves que apresentam uma dieta alimentar a base de insetos. A equabilidade das guildas foi relativamente baixa, o que indica variação das categorias analisadas (Vielliard e Silva 1990).

A predominância dessa guilda também foi encontrada por EFE (2001), que verificou uma presença maior de onívoros em relação aos insetívoros. A onivoria pode estar relacionada tanto à áreas antropizadas como também à áreas cobertas por vegetação secundária ou exótica (Willis 1979; D’angelo-Neto et al. 1998; Blamires et al. 2001), no entanto, Almeida (1982) menciona que o grande número de espécies onívoras em geral é maior nas matas menos 
alteradas, havendo o incremento do número de insetívoros nas mais alteradas. Segundo Lopes e Santos (2004) áreas com alterações de influências antrópicas podem influenciar a predominância de aves onívoras e insetívoras, assim como também pode haver decréscimo de frugívoros e até mesmo insetívoros mais especializados (Willis 1979). No entanto, essa última categoria compreende as espécies especializadas em forragear em determinados estratos e substratos da vegetação, insetívoros terrestres e de sub-bosque (Aleixo 2001).

A segunda guilda mais abundante foi a insetívora, os quais predominaram nas campanhas realizadas em período úmido, como foi o caso da primeira campanha onde os insetívoros apresentaram 36 espécies. Isso pode estar relacionado ao período de explosão reprodutiva dos artrópodes na região, que ocorre nesse período. O mesmo comportamento dos artrópodes foi encontrado em uma região mais úmida do país influenciando na biodiversidade encontrada (Bergallo e Magnusson 2002). Vieira et al. (2013) registraram em seu trabalho 112 espécies, sendo que as insetívoras representaram metade de todas as espécies (50\%), corroborando o resultado encontrado no presente estudo. As demais guildas tróficas (granívoras, nectívoras, carnívoras, piscívoras e detritívoras) compreenderam apenas $16 \%$ da avifauna.

Foi registrada na primeira amostra uma espécie de Dendrocolaptidae, (Xiphorhynchus guttatus) no mangue, no ponto amostral P1. Willis (1979) e Anjos (1998) citam que aves insetívoras escaladoras de tronco e galho (pica-paus e arapaçús), como a família Dendrocolaptidae, são localmente extintas mais rapidamente com a redução da área de forrageamento, característica esta que a torna sensível a alterações (Stouffer e Bierregaard Júnior 1995; Sigrist 2009). Aleixo e Vielliard (1995) apontaram os insetívoros especializados como o grupo de espécies mais sensível à fragmentação florestal, e comentam que o predomínio de insetívoros generalistas possivelmente é um padrão para a região Neotropical. Para Sekercioglu et al. (2002), aves insetívoras são mais susceptíveis às mudanças ambientais bruscas, se deslocando para outras áreas à procura de insetos, quando estes se tornam escassos.

As aves piscívoras e as que se alimentam de artrópodes aquáticos constituíram a terceira e quinta categorias tróficas mais abundante neste estudo. Com a chuva de janeiro a junho, áreas extensas são alagadas, tanto no entorno quanto no interior da usina, o que possibilita as condições necessárias para a manutenção e permanência das aves consideradas por este estudo como de lagos, rios e banhados, que visitam a área a procura de alimento (Guzzi et al. 2015). O padrão trófico da avifauna registrada no presente estudo apresenta similaridade a registrada nos trabalhos de Cardoso et al. (2013) e Guzzi et al. (2015), no qual as aves que se alimentam de artrópodes aquáticos e as piscívoras se apesentam entre as categorias mais abundantes. Nos estudos citados, a presença de hábitats aquáticos foram fatores que contribuíram para a presença dessas espécies. Segundo Luigi et al. (2010) áreas como mangues, brejos, rios, lagoas, pântanos, deltas e florestas, entre outras áreas de retenção de água, são potenciais atrativos para a avifauna limícolas.

No que se refere as aves que se alimentam de artrópodes aquáticos, o padrão encontrado pode ser comparado ao registrado na costa amazônica brasileira, onde a maior diversidade de aves limícolas em forrageio foi observada no habitat areno-lamoso, provavelmente devido a presença do banco de moluscos e da zona de caranguejos-uçá, os quais contribuíram para a existência de maior diversidade de presas. Diante disto, a proteção de habitats para aves limícolas requer planejamento em escala de paisagem, pois estas aves preferem um complexo de habitats integrados e próximos, tais como praias, habitats lamosos, areno-lamosos, arenosos e manguezais (Silva e Rodrigues 2015).

É importante ressaltar ainda a significante presença dos carnívoros nas quatro campanhas realizadas. Espécies da Ordem Accipitriformes e Falconiformes como as águias, falcões e gaviões, juntamente com os indivíduos da família Strigidae (corujas), são predadores topo de cadeia alimentar e, com exceção das espécies generalistas de borda e áreas abertas, estão em franco declínio populacional em virtude da fragmentação e simplificação dos habitats (Almeida e Almeida 1998).

Quanto à sensibilidade às alterações ambientais, houve a predominância de aves de baixa sensibilidade $(\mathrm{N}=75 ; 73.5 \%)$, ou seja, a maioria destas espécies conseguem permanecer em ambientes antropizados. As espécies consideradas como de média sensibilidade perfizeram um total de 24 espécies (23,5\%), e foram registradas três espécies de alta sensibilidade (3\%), sendo elas: Fregata magnificens, Charadrius collaris, Phaetusa simplex. Diante desse 
quadro, é importante concentrar as pesquisas científicas nas espécies mais sensíveis, buscando identificar as aves que tem maior risco de serem afetadas pelas turbinas dos aerogeradores (Desholm 2009).

Os dados corroboram estudos realizados, caracterizando possivelmente um padrão para a avifauna da região (Santos 2017; Nascimento 2018). A relevante quantidade de espécies com baixa sensibilidade às alterações ambientais pode ser explicada pelo fato de que as aves presentes que fazem parte do bioma Caatinga são naturalmente resistentes às alterações antrópicas (Stotz et al. 1996). Algumas características destas regiões, como o estresse causado pela irregularidade pluviométrica seleciona as espécies mais resistentes e menos exigentes (Silva et al. 2003) (Figura 2). A espécies com média sensibilidade foram a segunda mais representativa, este fato pode estar relacionado ao fato dessas espécies poderem alterar sua dinâmica populacional frente a impactos severos causados aos seus nichos ecológicos (Port e Fisch 2013).

Em relação ao uso do habitat, das espécies registradas, 67\% são classificadas como independentes (IN) quanto a seu habitat, 28\% são classificadas como semidependente e cinco espécies como dependentes, sendo elas: Eudocimus ruber, Calidris pusilla, Amaziilia versicolor, Campephilus melanoleucos e Psarocolius decumanus.

Em relação à baixa dependência das espécies aos ambientes florestais, este padrão também foi observado em área de transição entre Caatinga e Cerrado, no estado do Piauí (Santos 2008). De fato, estudos apontam que as espécies de aves da Caatinga são essencialmente independentes ou semidependentes de formações florestais (Santos 2001; Silva et al. 2003) e a maior parte é representada por espécies de baixa e média sensibilidade, assim como observado no presente estudo. Ainda é importante ressaltar que no geral a vegetação dos pontos amostrais são formações arbustivas de áreas mais abertas (Santos-Filho 2010), o que também pode explicar o perfil da avifauna local.

A sensibilidade, a riqueza e abundância, assim como a presença ou ausência de determinados grupos taxonômicos de aves, podem revelar informações importantes a respeito da qualidade de um determinado ambiente. Por isso, o conhecimento sobre o perfil da avifauna de uma região se faz tão importante (Angel-de-Oliveira 1993; Regalado e Silva 1997; Serrano 2008).

Figura 2. Gráficos de Guildas Tróficas (A), Sensibilidade a atividade Antrópicas (B), Uso do Hábitat (C) e Status (D).

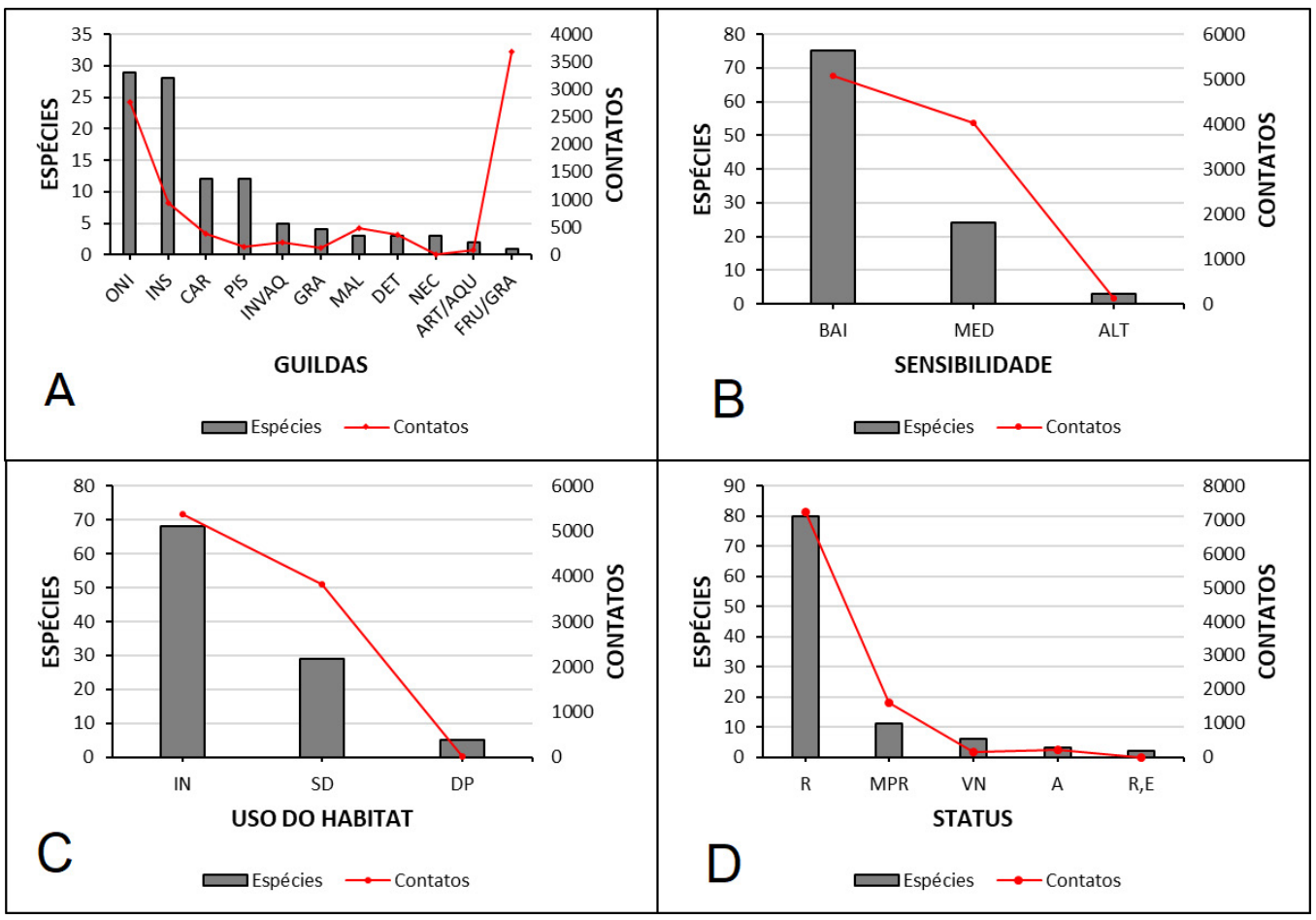

Fonte: Pesquisadora.

Legenda: (2A) ART/AQU: artrópodes aquáticos; CAR: Carnívoras; DET: Detritívoras; FRU/GRA= Frugívoras/Granívoras; GRA= Granívora; INS: Insetívoras; INVAQ: invertebrados aquáticos; MAL: Malacófagas; NEC= nectívoras; ONI: Onívoras; PIS: Piscívoras. (2B) $\mathrm{BAI}=$ Baixa; $\mathrm{MED}=$ Média; ALT = Alta. (2C) IN=Independente; $\mathrm{SD}=$ Semidependente; $\mathrm{DP}=$ dependente. (2D) $\mathrm{A}=\mathrm{Migrante}$ Austral; MPR= Residentes Parcialmente Migratórias; R=Residente; R,E=Residente Endêmica; VN=Vagante do Norte . 
Foi considerado o registro das espécies nos cinco pontos durante as quatro amostragens para o cálculo da frequência de ocorrência. Duas espécies foram abundantes, ocorrendo em $75 \%$ ou mais das amostras, sendo Pitangus sulphuratus ( $\mathrm{n}=82 \%$ ), seguido por Vanellus chilensis com $75 \%$ de frequência. Nove espécies foram comuns, 18 foram escassas e 57 espécies foram tidas como raras. As espécies que ocorreram somente uma vez em toda a amostragem foi considerada ocasional, essas totalizaram 16 espécies.

Muitas das espécies com baixa frequência de ocorrência na área de estudo vivem em ambientes de mata densa, o que pode explicar a irregularidade de seus registros nos pontos amostrais que estão inseridos em locais de vegetação típica de ambientes de restinga, denominadas por Santos-Filho et al. (2010) como formações arbustivas do tipo frutíceto aberto inundável. Possivelmente o tamanho do remanescente florestal não seja suficiente para suportar espécies mais especificas, que necessitam de ambientes mais diversificados com heterogeneidade de espécies vegetais, como é o caso dos frutívoros (Anjos 1999).

Também deve ser considerado que dentro de algumas categorias de frequência de ocorrência estão inseridas espécies migratórias e/ou vagantes, que por diversos motivos podem alterar suas rotas ou ter deslocamentos imprevisíveis, o que poderia afetar o registro das mesmas na área de estudo (Aleixo e Vielliard 1995).

Analisando as espécies mais frequentes na área de estudo, observa-se que a maioria é composta por aves de grande porte, como Theristicus caudatus, Cathartes burrovianus, Coragyps atratus, Rostrhamus sociabilis, Heterospizias meridionalis, Rupornis magnirostris e Caracara plancus. Estudos apontam que aves de grande porte estão mais propensas a sofrerem colisões e eletrocussões com estruturas artificiais como aerogeradores e linhas de transmissão (Janss 2000; Drewitt e Langston 2008; Oliveira et al. 2016). De fato, durante o esforço amostral na área de estudo, foram registrados quatro colisões de aves com os erogeradores dos parques (três indivíduos de Coragyps atratus e um indivíduso de Cathartes burrovianus). Foi possível perceber ainda aves de grande porte (Cathartes aura, Cathartes burrovianus, Coragyps atratus, Caracara plancus e Rupornis magnirostris) voando próximo dos aerogeradores.

Das espécies registradas, duas espécies apresentam algum grau de ameaça na lista da IUCN ou na lista nacional, sendo elas: Calidris pusilla e Conirostrum bicolor. Registrado exclusivamente pelo método de captura durante a terceira campanha, Calidris pusilla é classificada como em perigo (EN) pelo Ministério do Meio Ambiente (Brasil 2014) e quase ameaçada (NT) pela União Internacional para Conservação da Natureza (IUCN 2018). Procedente da América do Norte, é uma espécie migratória conhecida popularmente como maçarico-rasteirinho, varia entre 13$15 \mathrm{~cm}$ e peso de $20-41 \mathrm{~g}$, com envergadura de $34-37 \mathrm{~cm}$. Possui uma alimentação variada baseadas principalmente em invertebrados aquáticos e marinhos durante seu período de migração (Del Hoyo Elliott e Sargatal 1994; Sigrist 2009). A espécie Conirostrum bicolor é classificada como quase ameaçada pela União Internacional para Conservação da Natureza por se encontrar em declínio populacional, que tem como principal fator o desmatamento (IUCN 2018). Conhecida como figurinha-do-mangue, é uma espécie residente que ocupa os mangues desde costa atlântica da Venezuela ao estado do Paraná, no Brasil (Sick 1997).

Dentre os efeitos antrópicos presentes na região, a caça se destaca. Estudos realizados na área de influência do Complexo Eólico Delta do Parnaíba indicaram a caça como um dos principais fatores de impacto antrópico sobre a avifauna local. Algumas espécies registradas na área de estudo como Tigrisoma lineatum, Dendrocygna viduata e Aramus guarauna são alvo de caça na região, principalmente para alimentação. Enquanto espécies como Sturnella superciliaris, Thectocercus acuticaudatus, Turdus rufiventris e Icterus jamacaii geralmente são capturadas para criação em cativeiro (Santos 2017). No tocante à conservação, as aves canoras e os Psitaciformes atualmente são os grupos que mais sofrem com a captura e comercio ilegal no país e, além disso, a caça, bem como inúmeras ações antrópicas, vem causando a perda de diversidade biológica (Licarião et al. 2013). 


\section{Conclusão}

A região apresenta alteração na riqueza, abundância e composição de acordo com a cobertura da vegetação e o ciclo sazonal, devido a disponibilidade de recursos como água e alimento. A diversidade aumentou no período úmido, já durante o período seco ocorreu uma concentração da diversidade presente no ponto P1, devido sua constante disponibilidade de água e de alimento.

Os parques eólicos estudados apresentaram maior risco às aves de grande porte, e estas apresentaram maior interação com os parques, o que resultou no registro de quatro colisões de indivíduos da família Cathartidae, reforçando a ideia das aves de grande porte serem mais suscetíveis a acidentes com aerogeradores. A presença de espécies migratórias, sensíveis e dependentes de seus habitats demonstram a importância da região se fazendo necessário que haja planejamento para manutenção e funcionamento dos parques de modo a se minimizar os impactos, principalmente a diminuição da população ou as mudanças nas rotas das aves migratórias.

Duas espécies com grau de ameaça foram registradas nos parques estudados, o que reforça a importância do monitoramento de longo prazo de suas populações.

\section{Agradecimentos}

A CAPES pelo apoio financeiro.

\section{REFERÊNCIAS}

Aleixo A. 2001. Conservação da avifauna da Floresta Atlântica: efeitos da fragmentação e a importância de florestas secundárias. Ornitologia e conservação: da ciência às estratégias. Tubarão: Unisul, 199-206.

Aleixo A, Vielliard JME. 1995. Composição e dinâmica da avifauna da mata de Santa Genebra, Campinas, São Paulo, Brasil. Revista Brasileira de Zoologia, 12(3):493-511.

Almeida AF. 1982. Análise das categorias de nichos tróficos das aves de matas ciliares em Anhembi, Estado de São Paulo. Silvicultura, 15:1787-1795.

Almeida AF, Almeida A. 1998. Monitoramento de fauna e de seus habitats em áreas florestadas. Série Técnica IPEF, 12(31):85-92.

Andrade IM, Silva MFS, Simon JM, Silva AG, Silva APM, Braz GS, Nascimento HCE, Melo LMB, Costa MCA, Nascimento MGP, Reis RB, Santos RL. 2012. Diversidade de Fanerógamas do Delta Do Parnaíba - Litoral Piauiense. In: Guzzi, A (org). Biodiversidade do Delta do Parnaíba: litoral piauiense. Parnaíba: EDUFPI, p.63-115.

Anjos L. 1998. Conseqüências biológicas da fragmentação no norte do Paraná. IPEF, Piracicaba, 12(32):87-94.

Argel-de-Oliveira MM. 1993. Publicar ou não publicar? Listas de espécies são necessárias. Boletim CEO, 9:35-40.

Atauri JA, Lucio JV. 2001. The role of landscape structure in species richness distribuition of birds, amphibians, reptiles and lepidopterans in Mediterranean landscapes. Landscapes Ecology, 16(2):147-159. 
Barrios L, Rodriguez A. 2004. Behavioural and environmental correlates of soaring-bird mortality aton-shore wind turbines. Journal of Applied Ecology, 41(1):72-81.

Bergallo HG, Magnusson WE. 2002. Effects of weather and food availability on the condition and growth of two species of rodents in Southeastern Brazil. Mammalia, 6(1):17-31.

Bibby CJ, Burgess ND, Hill DA. 1992. Birds census techniques. London: Academic Press, 257p.

Bildstein KL, Bancroft GT, Dugan PJ, Gordon DH, Erwin RM, Nol E, Payne LX, Senner SE. 1991. Approaches to the conservation of coastal wetlands in the Western Hemisphere. The Wilson Bulletin, 103:218-254.

Blamires D, Valgas AB, Bispo PC. 2001. Estrutura da comunidade de aves da Fazenda Bonsucesso, município de Caldazinha, Goiás, Brasil. Tangara, 1(3):101-113.

Brasil. 1996. Decreto de 28 de agosto de 1996. Dispõe sobre a criação da Área de proteção Ambiental Delta do Parnaíba, nos estados do Piauí, Maranhão e Ceará, e dá outras providencias. Brasilia, DF, 29 de agosto de 1996. Disponível em: $<$ http:// www.planalto.gov.br/ccivil_03/dnn/anterior\%20a\%202000/1996/dnn4368.htm>. Acesso em: 16 de mai 2018.

Brasil. 2014. Ministério do Meio Ambiente. Lista de espécies. Disponível em:<http://www.icmbio.gov.br/portal/images/ stories/biodiversidade/fauna-brasileira/avaliacao-do-risco/PORTARIA_N\%C2\%BA_444_DE_17_DE_DEZEMBRO_ DE_2014.pdf > Acesso em: 06 de mar. de 2018.

Cabral SAS, Azevedo Júnior SM, Larrazábal ME. 2006. Levantamento das aves da Área de Proteção Ambiental de Piaçabuçu, no litoral de Alagoas, Brasil. Ornithologia. 1(2):161-167.

Camargo ASG. 2005. Análise da operação das usinas eólicas de Camelinho e Palmas e avaliação do potencial eólico de localidades no Paraná. Dissertação (Mestrado em Tecnologia) - Centro Federal de Educação Tecnológica do Paraná, Curitiba, 2005. 206f.

Cardoso CO, Santos AGS, Gomes DN, Tavares AA, Guzzi A. 2013. Análise e composição da avifauna no Aeroporto Internacional de Parnaíba, Piauí. Ornithologia, 6(1):89-101.

Castro AAJF. 2007. Unidade de planejamento: uma proposta para o estado do Piaú com base na dimensão diversidade de ecossistemas. Publicações Avulsas em Conservação de Ecossistemas, 18:1-28.

Cavarzere V, Moraes GP, Donatelli RJ. 2009. Avifauna da Estação Ecológica dos Caetetus, interior de São Paulo, Brasil. Papéis Avulsos de Zoologia, 49(35):477-485.

CEMAVE (Centro Nacional de Pesquisa e Conservação de Aves Silvestres). 2016. Relatório anual de rotas e áreas de concentração de aves migratórias no Brasil. Cabedelo, PB: CEMAVE/ ICMBio. 63p.

D'angelo-Neto S, Venturin N, Oliveira-Filho AT, Costa FAF. 1998. Avifauna de quatro fisionomias florestais de pequeno tamanho (5-8 ha) no Campus da UFLA. Revista Brasileira de Biologia, 58(3):463-472.

Del Hoyo J, Eliott A, Sargatal J (Eds.). 2011. Handbook of the birds of the world: Tanagers to the New World Blackbirds. Barcelona: Lynx Edicions, 16. 684p.

Del Hoyo J, Elliott A, Sargatal J. 1994. Handbook of the Birds of the World: New World Vultures to Guineafowl. Barcelona: Lynx Edicions, 2, 638p. 
Desholm M. 2009. Avian sensitivity to mortality: Prioritising migratory bird species for assessment at proposed wind farms. Journal of Environmental Management. 90(8):2672-2679.

Drewitt AL, Langston RHW. 2008. Collision effects of wind-power generators and other obstacles on birds. Annals of the New York Academy of Sciences, 1134:233-266.

Dunning JS. 1982. South American Land Birds. New York: Harrowood Books. 351p.

Efe M. 2001. Inventário e distribuição a avifauna do Parque Saint' Hilaire, Viamão, Rio Grande do Sul, Brasil. Tangara, Belo Horizonte, 1(1):12-25.

Gama TP, Sassi R. 2008. Aspectos do comércio ilegal de pássaros silvestres na cidade de João Pessoa, Paraíba, Brasil. Gaia Scientia, 2(2):1-20.

Guzzi A, Gomes DN, Santos AGS, Favretto MA, Soares LMS, Carvalho RAV. 2015. Composição e dinâmica da avifauna da usina eólica da praia da Pedra do Sal, Delta do Parnaíba, Piauí, Brasil. Iheringia. Série Zoologia (Online), 105:164173.

Guzzi A, Tavares AA, Santos AGS, Cardoso CO, Gomes DN, Machado JLC, Silva PC, Carvalho RAV, Vilarindo SG, Batista SCA. 2012. Diversidade de Aves do Delta do Parnaíba, Litoral Piauiense. In: GUZZI, A. (Org.). Biodiversidade do Delta do Parnaíba: litoral piauiense. Parnaiba: EDUFPI, 290-338.

IUCN. 2018. The IUCN Red List of Threatened Species. Versão 2018-2. Disponível em: < https://www.iucnredlist.org/ >. Acessado em: 25/11/2018.

Janss GFE. 2000. Avian mortality from power lines: a morphologic approach of a species-specific mortality. Biological Conservation, 95:353-359.

Köppen W. 1948. Climatologia: con un estudio de los climas de la tierra. México D.F.: Fondo de Cultura Econômica. 478p. Larrazábal ME, Azevedo-Júnior SM, Pena O. 2002. Monitoramento de aves limícolas na salina Diamante Branco, Galinhos, Rio Grande do Norte, Brasil. Revista Brasileira de Zoologia, 19(4):1081-1089.

Larsen JK, Clausen P. 2002. Potential wind park impact on whooper swans in winter: the risk of collision. Waterbirds Special Publication, 1(25):327-330.

Licarião MR, Bezerra DMM, Alves RRN. 2013. Wild birds as pets in Campina Grande, Paraíba State, Brazil: An Ethnozoological Approach, Anais da Academia Brasileira de Ciências, 85:201-213.

Lopes S, Santos RJ. 2004. Observação de aves: do ecoturismo à educação ambiental. Caminhos de Geografia, 5(13):103121.

Magurran, A.E. 1998. Ecological diversity and its measurement. New Jersey: Princeton University Press, 179 p.

Luigi G, Fonseca VS, Moura FH, Iob A. 2010. Metodologia de controle e redução da incidência de aves em aeroportos no Brasil. In: Von Mater S, Straube FC, Accordi IA, Piacentini VQ, Cândido-Junior JF (org). Ornitologia e Conservacão: Ciência Aplicada, Técnicas de Pesquisa e Levantamento. Rio de Janeiro: Technical Books, p. 429-439.

Lunardi OV. 2010. Estratégias de Forrageamento e Evitação de Predadores em Charadriidae e Scolopacidae na Bahia de Todos os Santos, Bhaia, Brasil. (Tese de Doutorado) Universidade de Brasília, Brasília, Brazil. 157p. 
Macías F, Nieto C, García A. 2003. Environmental impacts caused by eolic energy. Renewable Energy \& Power Quality Journal, 1(1).

Marçal Júnior O, Franchin AG, Alteff EF, Da Silva Junior L, De Melo C. 2009. Levantamento da avifauna na reserva ecológica Panga (Uberlândia, MG, Brasil). Bioscience Journal, 25(6):149-164.

Martins FR, Santos FAM. 1999. Técnicas usuais de estimativa da biodiversidade. Revista Holos, 1:236-267.

Motta-Junior JC. 1990. Estrutura trófica e composição da avifauna de três habitats terrestres na região central de São Paulo. Ararajuba, 1:65-71.

Nascimento MS. 2018. Impactos ambientais da linha de transmissão Delta: Tabuleiros sobre a avifauna, Piauí, Brasil. Dissertação (Mestrado Desenvolvimento e Meio Ambiente) - UFPI. Teresina, p. 92.

Naka LN, Rodrigues M, Roos AL, Azevedo MA. 2002. Bird conservation on Santa Catarina Island, Southern Brazil. Bird Conservation International, Cambridge, 12(1):123-150.

Nobrega VA, Barbosa JAA, Alves RN. 2012. Use of wild birds by residents of the municipality of Fagundes, in Paraiba's semiarid region: an ethnoornitologic approach. SITIENTIBUS, série Ciências Biológicas, 11(2):165-175.

Nunes CEC, MACHADO CG. 2012. Avifauna de duas áreas de caatinga em diferentes estados de conservação no Raso da Catarina, Bahia, Brasil. Revista Brasileira de Ornitologia, 20(3):215-229.

Oliveira AC, Barbosa AEA, Sousa AEBA, Paludo D, Lima DM, Nascimento JLX, Souza MA, Arantes MS, Serafini PP, Amaral PP, Rossato RM, Medeiros RCS. 2016. Relatório anual de rotas e áreas de concentração de aves migratórias no Brasil. Cabedelo, PB: CEMAVE/ ICMBio. 63p.

Oliveira AC, Barbosa AEA, Sousa AEBA, Paludo D, Lima DM, Nascimento JLX, Souza MA, Arantes MS, Serafini PP, Amaral PP, Rossato RM, Medeiros RCS. 2016. Relatório anual de rotas e áreas de concentração de aves migratórias no Brasil. Cabedelo, PB: CEMAVE/ ICMBio, 63 p.

Olmos F, Silva WAG, Albano CG. 2005. Aves em Oito Áreas de Caatinga no Sul do Ceará e Oeste de Pernambuco, Nordeste do Brasil: Composição, riqueza e similaridade. Papéis Avulsos de Zoologia, 45(14):179-199.

Piacentini VQ, Aleixo A, Agne CE, Maurício GN, Pacheco JF, Bravo GA, Brito GRR, Naka LN, Olmos F, Posso S, Silveira LF, Betini GS, Carrano E, Franz I, Lees AC, Lima LM, Pioli D, Schunck F, Amaral FR, Bencke GA, Cohn- Haft M, Figueiredo LFA, Straube FC, Cesari E. 2015. Annotated checklist of the birds of Brazil by the Brazilian Ornithological Records Committee. Revista Brasileira de Ornitologia, 23(2):90-298.

Port D, Fisch F. 2013. Aves da Reserva Biológica Municipal Moreno Fortes, Rio Grande do Sul, Brasil. Ornithologia, 5(2):92-107.

Regalado LB, Silva C. 1997. Utilização de aves como indicadores de degradação ambiental. Revista Brasileira de Ecologia, $1: 81-83$.

Ridgely RS, Tudor G. 1994. The birds of South America. Oxford: University Press, 2v.

Saidur R, Rahim NA, Islam MR, Solangi KH. 2011. Environmental impact of wind energy. Renewable and Sustainable Energy Reviews, 15(5):2423-2430. 
Santos FCV. 2017. Impactos ambientais do Complexo Eólico Delta do Parnaíba sobre a avifauna e os saberes etnoornitológicos na comunidade Labino, Piauí, Brasil. Dissertação (Mestrado Desenvolvimento e Meio Ambiente) UFPI. Teresina, 113p.

Santos MPD. 2001. Análise biogeográfica da avifauna de uma área de transição Cerrado-Caatinga no centro sul do Piauí, Brasil. (Dissertação de Mestrado). Programa de Pós-Graduação em Zoologia do MPEG/UFPA, 103p.

Santos MPD. 2008. Bird community distribution in a Cerrado- Caatinga transition área, Piauí, Brasil. Revista Brasileira de Ornitologia, 16(35):323-338.

Santos MPD, Cerqueira PV, Soares LMS. 2010. Avifauna em seis localidades no Centro-Sul do Estado do Maranhão, Brasil. Ornithologia, 4(1):49-65.

Santos SS. 2018. Impactos Ambientais do Perímetro Irrigado Tabuleiros Litorâneos do Piauí sobre a Avifauna. Dissertação (Mestrado em Desenvolvimento e Meio Ambiente) - UFPI. Teresina, 150p.

Santos-Filho FS, Almeida Junior EB, Soares CJRS, Zickel CS. 2010. Fisionomias das Restingas do Delta do Parnaiba, Nordeste, Brasil. Revista Brasileira de Geografia Física, 3(3):218-227.

Schaeffer- Novelli Y. (coord.). 1995. Manguezal: Ecossistema entre a Terra e o Mar. São Paulo: Caribbean Ecological Research, 64p.

Schaeffer-Novelli Y, Cintrón G. 1986. Guia para Estudos de Áreas de manguezal: estrutura, função \& flora. São Paulo, Caribbean Ecological Research, 150 p. e 3 apêndices.

Sekercioglu CH, Ehrlich PR, Daily GC, Aygen D, Goehring D, Sandí RF. 2002. Disappearance of insectivorous birds from tropical forest fragments. PNAS 99:263-267.

Sick H. 1983. Migrações de aves na América do Sul Continental. Brasília, Publicação Técnica CEMAVE - Instituto Brasileiro de Desenvolvimento Florestal, 395p.

Sick H. 1997. Ornitologia Brasileira. Edição revista e ampliada por José Fernando Pacheco. Editora Nova Fronteira, Rio de Janeiro, 862p.

Sigrist T. 2009. Avifauna brasileira: descrição das espécies. São Paulo: Avis Brasilis, 305p.

Silva JMC, Souza MA, Bieber AGD, Carlos CJ. 2003. Aves da Caatinga: Status, uso do habitat e sensitividade. In: Leal IR, Tabarelli M, Silva MC. (Eds.). Ecologia e conservação da Caatinga. Recife, PE: Ed. Universitária da UFPE, 237- 273.

Silva LMR, Rodrigues AAF. 2015. Densidade e distribuição espacial de aves limícolas em habitats de forrageio na costa amazônica brasileira. Cabedelo, Ornithologia, 8(1):17-21.

Silveira MHB, Machado CG. 2012. Estrutura da comunidade de aves em áreas de caatinga arbórea na Bacia do Rio Salitre, Bahia, Brasil. Revista Brasileira de Ornitologia, 20(3):161-172.

Stotz DF, Fitzpatrick JW, Parker TA, Moskovits DK. 1996. Neotropical Birds: Ecology and Conservation. Chicago: The University of Chicago Press, 478p. 
Stouffer PC, Bierregaard Junior RO. 1995. Use of Amazonian forest fragments by understory insectivorous birds. Ecology, Durham, 76(8): 2429-2445.

Telino-Junior WR, Azevedo-Junior SM, Lyra-Neves RM. 2003. Censo de aves migratórias (Charadriidae, Scolopacidae e Laridae) na Coroa do Avião, Igarassu, Pernambuco, Brasil. Revista Brasileira de Zoologia, 20(3):451-456.

Thelander CG, Smalwood KS, Rugge L. 2003. Bird Risk Behaviors and Fatalities at the Altamont Pass Wind Resource Area. Ojai, Califórnia. NREL, 83p.

Vieira FM, Purificação KN, Castilho LS, Pascotto MC. 2013. Estrutura Trófica de Quatro Fitofisionomias de Cerrado no Parque Estadual de Serra Azul. Ornithologia, 5(2): 43-57.

Vielliard JME, Silva WR. 1990. Nova metodologia de levantamento quantitativo da avifauna e primeiros resultados no interior do Estado de São Paulo, Brasil.In: Encontro Nacional dos Anilhadores de Aves, 4, Recife. Anais. Recife: Universidade Federal de Pernambuco, 151-171.

Walker JS. 2006. Resource use and rarity among frugivorous birds in a tropical rainforest on Sulawesi. Biological Conservation, 130: 60-69.

Willis EO. 1979. The composition of Avian Communities in Remanescent woodlots in Southern Brazil. Papéis Avulsos de Zoologia, 33:1-25.

Tabela 1. Lista de espécies registradas durante as quatro amostragens nos Parques Eólicos Testa Branca I e III.

\begin{tabular}{|c|c|c|c|c|c|c|c|c|c|}
\hline Ordem/Família/Espécie & $\begin{array}{l}\text { Nome em } \\
\text { Português }\end{array}$ & Status & Método & Guilda & SE & UH & $\begin{array}{l}\text { IUCN/ } \\
\text { MMA }\end{array}$ & $\begin{array}{l}\mathbf{N}^{\circ} \\
\text { IND }\end{array}$ & FO $\%$ \\
\hline \multicolumn{10}{|l|}{ ANSERIFORMES } \\
\hline \multicolumn{10}{|l|}{ ANATIDAE } \\
\hline $\begin{array}{l}\text { Dendrocygna viduata } \\
\text { (Linnaeus, 1766) }\end{array}$ & irerê & $\mathrm{R}$ & B & ONI & BAI & IN & $\mathrm{LC} / \mathrm{NA}$ & 4 & $7 \%$ \\
\hline $\begin{array}{l}\text { Amazonetta brasiliensis } \\
\text { (Gmelin, 1789) }\end{array}$ & ananaí & $\mathrm{R}$ & B & PIS & BAI & IN & $\mathrm{LC} / \mathrm{NA}$ & 2 & $4 \%$ \\
\hline $\begin{array}{l}\text { Cairina moschata (Linnaeus, } \\
1758 \text { ) }\end{array}$ & pato-do-mato & $\mathrm{R}$ & B & ONI & MED & IN & $\mathrm{LC} / \mathrm{NA}$ & 41 & $14 \%$ \\
\hline $\begin{array}{l}\text { Anas babamensis Linnaeus, } \\
1758\end{array}$ & $\begin{array}{l}\text { marreca- } \\
\text { toicinho }\end{array}$ & $\mathrm{R}$ & B & ONI & BAI & IN & $\mathrm{LC} / \mathrm{NA}$ & 4 & $11 \%$ \\
\hline \multicolumn{10}{|l|}{ PODICIPEDIFORMES } \\
\hline \multicolumn{10}{|l|}{ PODICIPEDIDAE } \\
\hline $\begin{array}{l}\text { Tachybaptus dominicus } \\
\text { (Linnaeus, 1766) }\end{array}$ & $\begin{array}{l}\text { mergulhão- } \\
\text { pequeno }\end{array}$ & $\mathrm{R}$ & B & PIS & MED & IN & $\mathrm{LC} / \mathrm{NA}$ & 4 & $4 \%$ \\
\hline \multicolumn{10}{|l|}{ SULIFORMES } \\
\hline \multicolumn{10}{|l|}{ FREGATIDAE } \\
\hline $\begin{array}{l}\text { Fregata magnificens } \\
\text { Mathews, } 1914\end{array}$ & tesourão & $\mathrm{R}$ & B & PIS & ALT & IN & $\mathrm{LC} / \mathrm{NA}$ & 1 & Ocasional \\
\hline \multicolumn{10}{|l|}{ PHALACROCORACIDAE } \\
\hline $\begin{array}{l}\text { Nannopterum brasilianus } \\
\text { (Gmelin, 1789) }\end{array}$ & biguá & $\mathrm{R}$ & B & PIS & BAI & IN & $\mathrm{LC} / \mathrm{NA}$ & 31 & $11 \%$ \\
\hline
\end{tabular}




\begin{tabular}{|c|c|c|c|c|c|c|c|c|c|}
\hline Ordem/Família/Espécie & $\begin{array}{l}\text { Nome em } \\
\text { Português }\end{array}$ & Status & Método & Guilda & SE & UH & $\begin{array}{c}\text { IUCN/ } \\
\text { MMA }\end{array}$ & $\begin{array}{l}\mathbf{N}^{\mathbf{o}} \\
\text { IND }\end{array}$ & FO $\%$ \\
\hline
\end{tabular}

\section{PELECANIFORMES}

\section{ARDEIDAE}

Tigrisoma lineatum

(Boddaert, 1783)

Nycticorax nycticorax

(Linnaeus, 1758)

Nyctanassa violacea

(Linnaeus, 1758)

Butorides striata (Linnaeus, 1758)

Bubulcus ibis (Linnaeus, 1758)

Ardea alba Linnaeus, 1758

Egretta tricolor (Statius

Muller, 1776)

Egretta thula (Molina,

1782)

Egretta caerulea (Linnaeus, 1758)

\section{THRESKIORNITHIDAE}

Eudocimus ruber (Linnaeus, 1758)

Theristicus caudatus

(Boddaert, 1783)

\section{CATHARTIFORMES}

\section{CATHARTIDAE}

Cathartes aura (Linnaeus, 1758)

\section{Cathartes burrovianus}

Cassin, 1845

Coragyps atratus (Bechstein, 1793)

\section{ACCIPITRIFORMES}

\section{PANDIONIDAE}

Pandion haliaetus (Linnaeus, 1758)

\section{ACCIPITRIDAE}

Elanus leucurus (Vieillot, 1818)

Rostrhamus sociabilis

(Vieillot, 1817)

Heterospizias meridionalis

(Latham, 1790)

Urubitinga urubitinga

(Gmelin, 1788)

Rupornis magnirostris

(Gmelin, 1788)

\section{GRUIFORMES}

\section{ARAMIDAE}

Aramus guarauna

(Linnaeus, 1766)

\section{RALLIDAE}

Gallinula galeata

(Lichtenstein, 1818)

\begin{tabular}{|c|c|c|c|c|c|c|c|c|}
\hline socó-boi & $\mathrm{R}$ & B & CAR & BAI & IN & $\mathrm{LC} / \mathrm{NA}$ & 5 & $11 \%$ \\
\hline $\begin{array}{c}\text { socó- } \\
\text { dorminhoco }\end{array}$ & $\mathrm{R}$ & B & PIS & BAI & IN & $\mathrm{LC} / \mathrm{NA}$ & 3 & $4 \%$ \\
\hline $\begin{array}{l}\text { savacu-de- } \\
\text { coroa }\end{array}$ & $\mathrm{R}$ & B & ONI & MED & SD & $\mathrm{LC} / \mathrm{NA}$ & 1 & Ocasion \\
\hline socozinho & $\mathrm{R}$ & $\mathrm{B}, \mathrm{C}$ & CAR & BAI & IN & $\mathrm{LC} / \mathrm{NA}$ & 77 & $50 \%$ \\
\hline garça-vaqueira & $\mathrm{R}$ & B & INS & BAI & IN & $\mathrm{LC} / \mathrm{NA}$ & 39 & $4 \%$ \\
\hline garça-branca & $\mathrm{R}$ & B & ONI & BAI & IN & $\mathrm{LC} / \mathrm{NA}$ & 211 & $39 \%$ \\
\hline garça-tricolor & $\mathrm{R}$ & B & ONI & MED & SD & $\mathrm{LC} / \mathrm{NA}$ & 19 & $4 \%$ \\
\hline $\begin{array}{l}\text { garça-branca- } \\
\text { pequena }\end{array}$ & $\mathrm{R}$ & B & ONI & BAI & IN & $\mathrm{LC} / \mathrm{NA}$ & 473 & $21 \%$ \\
\hline garça-azul & $\mathrm{R}$ & B & ONI & MED & IN & $\mathrm{LC} / \mathrm{NA}$ & 12 & $7 \%$ \\
\hline guará & $\mathrm{R}$ & B & MAL & BAI & IN & $\mathrm{LC} / \mathrm{NA}$ & 198 & $7 \%$ \\
\hline curicaca & A & B & INS & BAI & IN & $\mathrm{LC} / \mathrm{NA}$ & 204 & $43 \%$ \\
\hline
\end{tabular}

urubu-decabeçavermelha

B

DET

BA

IN

LC/NA

12

$29 \%$

urubu-de-

cabeça-

amarela

urubu

$\mathrm{R}$

B

DET

MED

IN

LC/NA

14

$36 \%$

$\mathrm{R}$

B

DET

BAI

IN

LC/NA

346

$64 \%$

\section{águia-} pescadora

$\mathrm{VN}$

B

PIS

MED

IN

LC/NA

2

$7 \%$

gavião-peneira

CAR

BAI

IN

LC/NA

1

Ocasional

gaviãocaramujeiro

MPR

B

MAL

BAI IN LC/NA

245

$32 \%$

gavião-

caboclo

R

B

CAR

BAI

IN LC/NA

17

$32 \%$

gavião-preto

R

B

CA

MED

SD

LC/NA

2

$7 \%$

gavião-carijó

R B,C

CAR

BAI

IN LC/NA

78

$61 \%$

carão

$\mathrm{R}$

B

MAL

MED

IN

LC/NA

34

$25 \%$

galinha-d'água

R

B

ONI

BAI

IN LC/NA

4

$4 \%$ 


\begin{tabular}{clccccccc}
\hline Ordem/Família/Espécie & $\begin{array}{l}\text { Nome em } \\
\text { Português }\end{array}$ & Status & Método Guilda & SE & UH & $\begin{array}{c}\text { IUCN/ } \\
\text { MMA }\end{array}$ & $\begin{array}{c}N^{\circ} \\
\text { IND }\end{array}$ & FO $\%$ \\
\hline
\end{tabular}

\section{CHARADRIIFORMES}

\section{CHARADRIIDAE}

Vanellus chilensis (Molina, 1782)

Charadrius semipalmatus

Bonaparte, 1825

quero-quero MPR

batuíra-debando

Charadrius collaris Vieillot, 1818

\section{RECURVIROSTRIDAE}

Himantopus mexicanus

(Statius Muller, 1776)

\section{SCOLOPACIDAE}

Actitis macularius

(Linnaeus, 1766)

Tringa melanoleuca (Gmelin, 1789)

Tringa flavipes (Gmelin, 1789)

Calidris pusilla (Linnaeus, 1766)

\section{JACANIDAE}

Jacana jacana (Linnaeus, 1766)

\section{STERNIDAE}

Sternula antillarum Lesson, 1847

Sternula superciliaris

(Vieillot, 1819)

Phaetusa simplex (Gmelin, 1789)

\section{COLUMBIFORMES}

\section{COLUMBIDAE}

Columbina talpacoti

(Temminck, 1810)

Columbina passerina

(Linnaeus, 1758)

Columbina squammata

(Lesson, 1831)

Columbina picui

(Temminck, 1813)

\section{CUCULIFORMES}

\section{CUCULIDAE}

Crotophaga major Gmelin, 1788

Crotophaga ani Linnaeus, 1758

Guira guira (Gmelin, 1788)

\section{STRIGIFORMES}

\section{TYTONIDAE}

Tyto furcata (Temminck, 1827)

batuíra-de-

coleira

$\mathrm{VN}$

$\mathrm{R}$

pernilongo-

de-costas-

brancas

maçaricopintado

maçarico-

grande-de-

$\mathrm{VN}$

maçarico-de-

perna-amarela

rasteirinho

$\mathrm{VN}$

jaçanã

trinta-réismiúdo

R

trinta-réis-

pequeno

A grande

$\mathrm{R}$

rolinha
rolinha-
cinzenta

$\mathrm{R}$

MPR

fogo-apagou

$\mathrm{R}$

rolinha-picuí

A

suindara

$\mathrm{R}$
R B,C

INVAQ

MED

IN

LC/NA

90

$14 \%$

$\mathrm{VN} \quad \mathrm{B}, \mathrm{C}$

INVAQ

BAI

IN

LC/NA

49

$14 \%$

perna amarela

B

INVAQ

BAI

IN LC/NA

27

$11 \%$

$\mathrm{VN} \quad \mathrm{B}$

INVAQ

BAI

IN LC/NA

52

$21 \%$

maçarico-

C

INVAQ

MED DP NT/EN 1

Ocasional

$\mathrm{R} \quad \mathrm{B}, \mathrm{C}$

ONI

BA

IN

LC/NA

88

$32 \%$

B

PIS

B

PIS

MED

$\mathrm{SD}$

LC/NA

BA

IN

$\mathrm{LC} / \mathrm{N}$

ALT

IN LC/NA

B

PIS

AIT

B

GRA

BAI

IN

$\mathrm{LC} / \mathrm{NA}$

3

$7 \%$

B

GRA

BAI

IN LC/NA

42

$39 \%$

B,C

GR

MED

IN LC/NA 88

$32 \%$

B

GRA

BAI

$$
\text { IN }
$$

LC/NA

1

Ocasional

$\begin{array}{ccccccccc}\text { anu-coroca } & \text { MPR } & \text { B } & \text { ONI } & \text { BAI } & \text { IN } & \text { LC/NA } & 103 & 32 \% \\ \text { anu-preto } & \text { R } & \text { B,C } & \text { ONI } & \text { BAI } & \text { IN } & \text { LC/NA } & 192 & 50 \% \\ \text { anu-branco } & \text { R } & \text { B } & \text { INS } & \text { BAI } & \text { IN } & \text { LC/NA } & 230 & 68 \%\end{array}$

B

CAR

BAI

IN LC/NA

2

$7 \%$ 


\begin{tabular}{|c|c|c|c|c|c|c|c|c|c|}
\hline Ordem/Família/Espécie & $\begin{array}{l}\text { Nome em } \\
\text { Português }\end{array}$ & Status & Método & Guilda & SE & $\mathbf{U H}$ & $\begin{array}{c}\text { IUCN/ } \\
\text { MMA }\end{array}$ & $\begin{array}{l}\mathbf{N}^{\mathbf{o}} \\
\text { IND }\end{array}$ & FO $\%$ \\
\hline
\end{tabular}

\section{STRIGIDAE}

Athene cunicularia (Molina, 1782)

coruja-
buraqueira
corujinha-do-
mato

R B

\section{CAR}

MED IN

LC/NA

$\mathrm{R}$

B

CAR

BAI

$\mathrm{SD}$ LC/NA 1

Ocasional

Megascops
1817 )

mato

\section{CAPRIMULGIFORMES}

\section{CAPRIMULGIDAE}

Nyctidromus albicollis

(Gmelin, 1789)

bacurau

$\mathrm{R} \quad \mathrm{B}, \mathrm{C}$

INS

BAI

SD

LC/NA

10

$11 \%$

Hydropsalis parvula (Gould, 1837)

bacurau-

MPR

B,C

INS

BAI SD LC/NA 11

$14 \%$

Hydropsalis torquata

(Gmelin, 1789)

bacurau-

$\mathrm{R}$

B INS

BA

IN

LC/NA 2

$4 \%$

bacurau-de-

MPR

B

INS

BAI IN LC/NA 5

$4 \%$

\section{APODIFORMES}

\section{TROCHILIDAE}

Amarilia leucogaster

(Gmelin, 1788)

Amazilia fimbriata

(Gmelin, 1788)

beija-flor-de-
barriga-branca
beija-flor-
de-garganta-
verde
beija-flor-de-
banda-branca

$\mathrm{R}$

B,C

NEC

BAI

IN

LC/NA

4

$11 \%$

Amazilia versicolor (Vieillot, 1818)

$\mathrm{R}$

B NEC

BA

SD

LC/NA

1

Ocasional

$\mathrm{R}$

C NEC

BAI

DP LC/NA

1

Ocasional

\section{CORACIIFORMES}

\section{ALCEDINIDAE}

Megaceryle torquata

(Linnaeus, 1766)

Chloroceryle amazona

(Latham, 1790)

Chloroceryle americana

(Gmelin, 1788)

\section{GALBULIFORMES}

\section{BUCCONIDAE}

Nystalus maculatus

(Gmelin, 1788)

\section{PICIFORMES}

\section{PICIDAE}

martim-

pesca grande

martim-

pescadorverde

martim-

pescadorpequeno

$\mathrm{R} \quad \mathrm{B}, \mathrm{C} \quad$ PIS

BAI

IN

LC/NA

58

$46 \%$

$\mathrm{R} \quad \mathrm{B}, \mathrm{C} \quad$ PIS

BAI

SD LC/NA

6

$21 \%$

rapazinhodos-velhos

R, E B

INS

MED

SD

D

$\mathrm{C} / \mathrm{NA}$

Ocasional

Melanerpes candidus (Otto, 1796)

pica-paubranco

Campephilus melanoleucos

(Gmelin, 1788)

pica-pau-

de-topetevermelho

$\mathrm{R}$

$\mathrm{R}$

B

INS

BA

$\mathrm{D}$

FALCONIDAE

Caracara plancus (Miller, 1777)

carcará

$\mathrm{R}$

B

CAR

BAI

IN

carrapateiro

R

B

CAR

BAI

IN

CAR

BAI

Falco sparverius Linnaeus, 1758

quiriquiri

R B




\begin{tabular}{ccccccccc}
\hline Ordem/Família/Espécie & $\begin{array}{l}\text { Nome em } \\
\text { Português }\end{array}$ & Status & Método Guilda & SE & UH & $\begin{array}{c}\text { IUCN/ } \\
\text { MMA }\end{array}$ & $\begin{array}{c}N^{\circ} \\
\text { IND }\end{array}$ & FO $\%$ \\
\hline
\end{tabular}

\section{PSITTACIFORMES}

PSITTACIDAE

Thectocercus acuticaudatus (Vieillot, 1818) aratinga-detesta-azul
R B FRU/

MED SD LC/NA 3682

$68 \%$

\section{PASSERIFORMES}

\section{THAMNOPHILIDAE}

Formicivora melanogaster

Pelzeln, 1868

Taraba major (Vieillot, 1816)

\section{DENDROCOLAPTIDAE}

Xiphorbynchus guttatus

(Lichtenstein, 1820)

\section{FURNARIIDAE}

Certhiaxis cinnamomeus

(Gmelin, 1788)

\section{TYRANNIDAE}

Myiarchus ferox (Gmelin, 1789)

Myiarchus tyrannulus (Statius Muller, 1776)

Pitangus sulphuratus

(Linnaeus, 1766)

Machetornis rixosa (Vieillot, 1819)

Myiozetetes cayanensis

(Linnaeus, 1766)

Myiozetetes similis (Spix 1825)

Tyrannus melancholicus Vieillot, 1819

Fluvicola nengeta (Linnaeus, 1766)

\section{HIRUNDINIDAE}

Progne tapera (Vieillot, 1817)

Tachycineta albiventer

(Boddaert, 1783)

\section{TROGLODYTIDAE}

Troglodytes musculus

Naumann, 1823

\section{POLIOPTILIDAE}

Polioptila plumbea (Gmelin, 1788)

\section{formigueiro- de-barriga- preta \\ choró-boi \\ arapaçu-de- \\ garganta-}

B

$\mathrm{R}$

amarela

curutié

R

maria-

cavaleira

$\mathrm{R}$

B

INS

BAI

SD

maria-

cavaleira-

de-rabo-

enferrujado

bem-te-vi

MPR

suiriri-

cavaleiro

$\mathrm{R}$

bentevizinhode-asaferrugínea

bentevizinhode-penachovermelho

suiriri
lavadeira-
mascarada

andorinha-docampo

andorinha-

do-rio

corruíra

$\mathrm{R}$

B

ONI

BA

IN

$11 \%$

balança-rabode-chapéupreto
R B

INS

MED

$\mathrm{SD} \mathrm{LC} / \mathrm{NA}$

9 


\begin{tabular}{|c|c|c|c|c|c|c|c|c|c|}
\hline Ordem/Família/Espécie & $\begin{array}{l}\text { Nome em } \\
\text { Português }\end{array}$ & Status & Método & Guilda & SE & UH & $\begin{array}{l}\text { IUCN/ } \\
\text { MMA }\end{array}$ & $\begin{array}{l}\mathbf{N}^{\circ} \\
\text { IND }\end{array}$ & $\mathbf{F O} \%$ \\
\hline \multicolumn{10}{|l|}{ TURDIDAE } \\
\hline $\begin{array}{l}\text { Turdus rufiventris Vieillot, } \\
1818\end{array}$ & $\begin{array}{c}\text { sabiá- } \\
\text { laranjeira }\end{array}$ & $\mathrm{R}$ & B & ONI & BAI & IN & $\mathrm{LC} / \mathrm{NA}$ & 2 & $7 \%$ \\
\hline $\begin{array}{l}\text { Turdus amaurochalinus } \\
\text { Cabanis, } 1850\end{array}$ & sabiá-poca & $\mathrm{R}$ & B & ONI & BAI & SD & LC/NA & 2 & $4 \%$ \\
\hline $\begin{array}{l}\text { Turdus lencomelas Vieillot, } \\
1818\end{array}$ & sabiá-branco & $\mathrm{R}$ & $\mathrm{B}, \mathrm{C}$ & ONI & BAI & $\mathrm{SD}$ & LC/NA & 3 & $7 \%$ \\
\hline \multicolumn{10}{|l|}{ MIMIDAE } \\
\hline $\begin{array}{l}\text { Mimus gilvus (Vieillot, } \\
\text { 1807) }\end{array}$ & sabiá-da-praia & $\mathrm{R}$ & B & ONI & BAI & IN & LC/NA & 170 & $71 \%$ \\
\hline $\begin{array}{l}\text { Mimus saturninus } \\
\text { (Lichtenstein, 1823) }\end{array}$ & $\begin{array}{l}\text { sabiá-do- } \\
\text { campo }\end{array}$ & $\mathrm{R}$ & B & ONI & BAI & IN & LC/NA & 5 & $7 \%$ \\
\hline \multicolumn{10}{|l|}{ MOTACILLIDAE } \\
\hline $\begin{array}{l}\text { Antbus lutescens Pucheran, } \\
1855\end{array}$ & $\begin{array}{l}\text { caminheiro- } \\
\text { zumbidor }\end{array}$ & $\mathrm{R}$ & B & INS & BAI & IN & $\mathrm{LC} / \mathrm{NA}$ & 228 & $61 \%$ \\
\hline \multicolumn{10}{|l|}{ ICTERIDAE } \\
\hline $\begin{array}{l}\text { Psarocolius decumanus } \\
\text { (Pallas, 1769) }\end{array}$ & japu & $\mathrm{R}$ & B & ONI & MED & DP & $\mathrm{LC} / \mathrm{NA}$ & 1 & Ocasional \\
\hline $\begin{array}{l}\text { Procacicus solitarius (Vieillot, } \\
\text { 1816) }\end{array}$ & $\begin{array}{l}\text { iraúna-de- } \\
\text { bico-branco }\end{array}$ & $\mathrm{R}$ & B & ONI & BAI & SD & $\mathrm{LC} / \mathrm{NA}$ & 2 & $4 \%$ \\
\hline $\begin{array}{l}\text { Cacicus cela (Linnaeus, } \\
1758 \text { ) }\end{array}$ & xexéu & $\mathrm{R}$ & B & INS & BAI & IN & $\mathrm{LC} / \mathrm{NA}$ & 3 & $7 \%$ \\
\hline $\begin{array}{l}\text { Icterus pyrrhopterus (Vieillot, } \\
\text { 1819) }\end{array}$ & encontro & $\mathrm{R}$ & B & ONI & MED & SD & LC/NA & 3 & $7 \%$ \\
\hline $\begin{array}{l}\text { Icterus jamacaii (Gmelin, } \\
\text { 1788) }\end{array}$ & corrupião & R, E & B & ONI & MED & SD & $\mathrm{LC} / \mathrm{NA}$ & 4 & $11 \%$ \\
\hline $\begin{array}{l}\text { Chrysomus ruficapillus } \\
\text { (Vieillot, 1819) }\end{array}$ & garibaldi & $\mathrm{R}$ & B & ONI & BAI & $\mathrm{IN}$ & $\mathrm{LC} / \mathrm{NA}$ & 100 & $25 \%$ \\
\hline $\begin{array}{l}\text { Molotbrus bonariensis } \\
\text { (Gmelin, 1789) }\end{array}$ & chupim & $\mathrm{R}$ & B & ONI & BAI & $\mathrm{IN}$ & $\mathrm{LC} / \mathrm{NA}$ & 22 & $7 \%$ \\
\hline $\begin{array}{l}\text { Sturnella superciliaris } \\
\text { (Bonaparte, 1850) }\end{array}$ & $\begin{array}{l}\text { polícia- } \\
\text { inglesa-do-sul }\end{array}$ & $\mathrm{R}$ & B & ONI & BAI & IN & $\mathrm{LC} / \mathrm{NA}$ & 116 & $39 \%$ \\
\hline \multicolumn{10}{|l|}{ THRAUPIDAE } \\
\hline $\begin{array}{l}\text { Conirostrum bicolor (Vieillot, } \\
1809 \text { ) }\end{array}$ & $\begin{array}{l}\text { figuinha-do- } \\
\text { mangue }\end{array}$ & $\mathrm{R}$ & C & INS & BAI & $\mathrm{SD}$ & NT/NA & 8 & $11 \%$ \\
\hline $\begin{array}{l}\text { Conirostrum b. bicolor } \\
\text { (Vieillot, 1809) }\end{array}$ & $\begin{array}{l}\text { figuinha-do- } \\
\text { mangue }\end{array}$ & $\mathrm{R}$ & C & INS & BAI & $\mathrm{SD}$ & NT/NA & 3 & $4 \%$ \\
\hline $\begin{array}{l}\text { Conirostrum b. minus } \\
\text { (Hellmayr, 1935) }\end{array}$ & $\begin{array}{l}\text { figuinha-do- } \\
\text { mangue }\end{array}$ & $\mathrm{R}$ & C & INS & BAI & $\mathrm{SD}$ & NT/NA & 1 & Ocasional \\
\hline \multicolumn{10}{|l|}{ PASSERIDAE } \\
\hline $\begin{array}{l}\text { Passer domesticus (Linnaeus, } \\
\text { 1758) }\end{array}$ & pardal & $\mathrm{R}$ & B & ONI & BAI & IN & LC/NA & 4 & $4 \%$ \\
\hline
\end{tabular}

Fonte: Pessoal.

LEGENDA: Status: R: Residente R,E: Residente Endêmica, VN: Vagante do Norte, MPR: Residente Parcialmente Migratória. Guilda: Categorias Tróficas da avifauna registrada. INS: Insetívoras; ONI: Onivoras; CAR: Carnívoras; PIS: Piscívoras; GRA: Granívoras; MAL: Malacófagas; INVAQ: Invertebrados Aquáticos; ART/AQU: Artrópodes aquático; FRU/GRA: Frutívora, Granívora; NEC: Nectívora e DET: Detritívora. Método de registro: C: Captura; B: Busca ativa. SE: Sensitividade a distúrbios humanos: BAI: Baixa; MED; Média; ALT: Alta. UH: Uso do habitat: IN: Espécie independente de ambientes florestais; SD: Espécie semidependente de ambientes florestais; DP: Espécie dependente de ambientes florestais. FO\%: Frequência de ocorrência (percentual) 